\title{
Office Work and Complaints of the Arms, Neck and Shoulders: The Role of Job Characteristics, Muscular Tension and Need for Recovery
}

\author{
Jason C. Gawke, Marjan J. Gorgievski and Dimitri van der Linden \\ Department of Work and Organizational Psychology, Erasmus University Rotterdam, The Netherlands
}

\begin{abstract}
Office Work and Complaints of the Arms, Neck and Shoulders: The Role of Job Characteristics, Muscular Tension and Need for Recovery: Jason C. GAWKE, et al. Department of Work and Organizational Psychology, Erasmus University Rotterdam, The Netherlands-Objectives: This study investigated physical, psychological and social job characteristics as potential risk factors for complaints of the arms, neck and shoulders (CANS) and mediating effects of muscular tension and need for recovery. Methods: Data were collected among 105 computer workers using questionnaires and electromyography (EMG), and were analyzed with linear regression analyses. Results: Task interdependence, information processing and lower social support predicted more CANS. Physical job demands had no predictive power over and above psychological and social stressors. Both muscular tension and need for recovery partially mediated the job characteristics - CANS relationships. Conclusions: Occupational health professionals should not neglect psychological and social job characteristics as potentially important predictors of CANS in specific occupational groups, such as office workers. Our findings imply that CANS interventions should not be restricted to ergonomic improvements, but should be accompanied by improvement of the job design from a psychological and social perspective and reactive intervention aimed at decreasing short-term physical strain (muscular tension) and mental strain (need for recovery).
\end{abstract}

(J Occup Health 2012; 54: 323-330)

Key words: Job design, Muscle tension, Musculoskeletal disorders, Need for recovery, Upper extremity, Workplace

Received Jul 21, 2011; Accepted Apr 3, 2012

Published online in J-STAGE May 18, 2012

Correspondence to: M. Gorgievski, Erasmus University Rotterdam, Department of Work and Organizational Psychology, T13-03, P.O. Box 1738, NL-3000 DR Rotterdam, The Netherlands (e-mail: Gorgievski@fsw.eur.nl)
Work-related disorders of the upper limbs, also known as work-related upper extremity disorders (WRUED), or in more recent terminology, complaints of the arms, neck and/or shoulder (CANS) ${ }^{1)}$, are among the most common occupational diseases in modern society ${ }^{2}$. For example, in 2005, musculoskeletal disorders covered about 39 per cent of recognized occupational diseases in Europe, accounting for a substantial proportion of work-related absence and days lost. Studies have estimated that the cost of CANS is between $0.5 \%$ and $2 \%$ of gross national product $^{3)}$. Not surprisingly, discovering CANS risk factors has become an important goal in occupational health research.

CANS is affected by several factors in the work environment. Presuming physical factors would be the primary cause, early research has mainly focused on physical aspects of the environment, such as the optimization of equipment and work posture, and physical work demands ${ }^{4}$. Recently, psychological and social risk factors in the work environment have also been investigated, but results are still inconclusive ${ }^{5-10)}$. Moreover, only a restricted number of psychological and social factors have been studied, typically quantitative work load, job control and social support. Some important limitations in previous research on this topic are that i) most studies to date have investigated the role of different factors in isolation, and that ii) insights into mediating mechanisms in the relationship between job design and CANS are scarce. Therefore, the aim of our study was to contribute to this research area by examining within a single study the relationships between exposure to physical as well as psychological and social risk factors and CANS and investigating the possible mediating role of shortterm strain, specifically muscular tension and need for recovery.

\section{Theoretical background}

The theoretical background of this study is based 
on the Effort-Recovery (ER) model ${ }^{11)}$. According to this model, poor job design characterized by an imbalance between job demands-physical, psychological, social and organizational aspects of work that impose psychological and physiological costs on the employee - and job resources-motivational work aspects that decrease the above mentioned costs-predicts temporary, psychological and physical health complaints, such as mental fatigue and increased muscular tension. These short-term responses do not necessarily lead to health complaints, such as CANS, when employees are able to recover from the strain effects. Only repeated exposure to risk factors or an inability to recover from short-term strain is expected to increase the risk of developing long-term symptoms.

\section{Job characteristics as predictors of CANS}

In previous research, physical demands and poor psychological and social job design have been reported as risk factors for CANS. Physical demands pertain to, for example, working in a static posture for a prolonged period of time, repeated movements and high muscular effort. A prolonged static posture can result in muscular fatigue, and both repeated movements and high muscular effort can damage the tendon sheaths, which may eventually result in CANS $^{5)}$. So, ample evidence supports the notion that physical demands can result in $\mathrm{CANS}^{7,12-21)}$.

Theoretical scholarly articles have also identified possible mechanisms through which psychological and social job characteristics may lead to an increased susceptibility to CANS as well ${ }^{22,23)}$. Examples include hormonal, circulatory and respiratory stress responses or employees' attitudinal, motivational and behavioral stress responses that may increase CANS risk, such as working with more muscular effort than required for the task, or a subjectively increased experience of pain (pain intolerance), impairment and disability related to CANS.

Concerning empirical evidence, studies have indeed found that psychological and social job characteristics relate to CANS, yet literature reviews show inconclusive results ${ }^{7-10)}$. Overall, stronger evidence was found for an effect of high psychological job demands (i.e., time pressure, role conflict and a hectic job) ${ }^{12,24-27)}$ and low job discretion ${ }^{12,13,27)}$, and less evidence for social aspects of the job, for example, for low coworker support ${ }^{24)}$, low supervisor support ${ }^{25)}$, poor communication quality ${ }^{28)}$ and little interaction with others $^{21}$. To illustrate, in a prospective cohort study ${ }^{24)}$, high job demands related to self-reported complaints of the neck and shoulder as well as elbow, wrist and hand, whereas low coworker support only related to complaints of the elbow, wrist and hand. These relationships were partly mediated by increased exposure to physical risk factors. In contrast, another study found that psychological job demands predicted selfreported complaints in the neck and shoulder, but not the arms, wrist and hands ${ }^{29}$. Similarly, a prospective study in industry and service companies ${ }^{12)}$ showed that psychological job demands and job control, but not social work factors, were related to neck and shoulder pain. Moreover, the effect of job control was not significant over and above physical and psychological demands.

Because few studies have analyzed the effects of physical, psychological and social risk factors in an integrated manner, the question remains as to whether psychological and social job characteristics might explain CANS over and above physical risk factors $^{26,27)}$. In this study it is assumed that different mechanisms may underlie the effects of physical versus psychological and social risk factors, and hence we expect additive effects:

Hla: Physical job demands relate to more CANS.

H1b: Psychological and social job demands relate to more CANS.

H1c: Psychological and social job resources relate to less CANS.

\section{The mediating role of short-term strain}

Based on our contention that CANS are a long-term result of repeated or prolonged exposure to a stressor, it can be expected that poor work design first results in short-term physical and psychological reactions, which may develop into long-term strain effects over time. One possibility is that job demands and lack of resources relate to increased muscular tension, which could eventually result in CANS ${ }^{23}$. Previous research has examined the relationship between work characteristics and muscular tension, both using electromyography (EMG) and subjective measurements of muscular tension $^{26,30-32)}$. In a laboratory experiment, Lundberg et al. found support for a positive relationship between performing a physical task, a mental arithmetic task and a Stroop test, and on the other hand increased EMG activity in the trapezius muscle ${ }^{30)}$. In contrast, Vasseljen and Westgaard found no relationship between perceived general tension and increased EMG activity in the trapezius muscle on the active side for computer workers ${ }^{31)}$. In this study, muscular tension during rest was the strongest differentiating factor between workers feeling neck pain and workers feeling no neck pain. Likewise, a study by Rietveld et al. showed that repetitive tasks increase muscular tension, which was a risk factor for $\mathrm{CANS}^{32}$. None of the above studies has actually tested for a mediation effect; that is, none of them examined whether the relationship between demands and CANS can be 
explained by muscular tension. Therefore we will test the following hypothesis:

\section{H2: Muscular tension mediates the relationship between job demands and CANS.}

Work characteristics may not only lead to shortterm physical strain but also to short-term psychological strain, such as fatigue and need for recovery. The latter refers to a person's desire to be temporarily relieved from demands in order to restore his or her resources. Short-term psychological strain may be an early warning signal related to, for example, hormonal excretion draining physical and psychological resources ${ }^{22}$. Concerning a possible mediating role of psychological short-term strain in the relationship between work characteristics and musculoskeletal problems, empirical results are again inconclusive. In a prospective cohort study ${ }^{24)}$, psychological and social job characteristics related to self-reported complaints of neck, shoulder and elbow partly through increased emotional exhaustion. Hoogendoorn et al. found little evidence for an intermediate effect of psychological strain in the relationship between psychological and social job characteristics and self-reported low-back pain $^{33)}$. Among assembly workers, but not among hospital workers, Kjellberg and Wadman found the relationship between self-reported demands and selfreported CANS and musculoskeletal complaints to be fully mediated by short-term affective stress respons$\mathrm{es}^{27,33)}$. Bystrom et al. found partial mediation effects for short-term physical discomfort and lack of motivation, which are both aspects of fatigue, in the relationship between psychological workload and self-reported CANS $^{35)}$. Based on these previous reports, the present study will examine whether the relationships between job characteristics and CANS are mediated by need for recovery.

\section{H3: Need for recovery mediates the relationship between job demands and CANS.}

In sum, the main purpose of our study is to investigate the relationships between work-related physical demands, psychological and social job characteristics and CANS and examine a possible mediating role of short-term physical and psychological strain. As our sample consists of office workers, we will particularly focus on high-risk physical demands related to computer work, such as a prolonged static position and repetitive movements, and psychological and social job characteristics typical for office work, namely task complexity, information processing-the extent to which someone has to interpret and monitor incoming information to make a response suitable within the context of an objective, problem or situation-and task interdependence. For job resources, we will focus on decision latitude, social support and task variety.

\section{Methodology}

Subject and methods

This study was conducted among 111 office workers at a large local government office in the Netherlands, whom worked at least six hours a day behind a computer (response rate $=88 \%$ ). Similar to the majority of offices in the Netherlands, already much attention had been paid to ergonomic factors, such as ergonomic office furniture, and there were relatively strict regulations regarding health risks of computer work. The study was brought to the employees' attention through the local department website, where they could also sign up for the study. After signing up, the employees received an email with a link to an online questionnaire. After they had filled out the questionnaire, an appointment was made for the EMG measurement. The data were stored anonymously; questionnaire data were connected to EMG measures using a unique individual code only the respondents knew. Participants were assured absolute confidentiality, and they were free to participate and to withdraw their participation at any time. Participants did not run any risk of physical harm, for example, from the EMG apparatus. Data were collected in the period May to June, 2010. The study was approved by the company's ethics committee, including a medical officer, a human resource officer and the head of the department. The major reasons for non-response were lack of interest in the topic and feeling uneasy about being connected to the EMG apparatus. Approximately $70 \%$ of the workers in this group were female. The mean age of the workers was $40.84 \mathrm{yr}(\mathrm{SD}=11.28)$. Time in service was on average $7.17 \mathrm{yr}(\mathrm{SD}=8.97)$.

\section{Measurements}

All subjective measures of job characteristics and strain showed good Cronbach's alpha reliability (see Table 1).

Complaints of the arms, neck and shoulders were measured with an abridged 7-item version of the "Dutch Musculoskeletal Questionnaire" (DMQ) ${ }^{36)}$. Respondents were shown a schematic picture of a human body with different regions pointed out with arrows and asked to rate the occurrence of complaints (pain or discomfort) in the arms, neck and shoulders in the previous 12 months. The rating scale ranged from 1 (never) to 4 (all the time). The scores on all items were averaged to calculate the total CANS score. 
Physical job demands were measured with 15 items of the DMQ on physical load (posture, movements and forces related to the upper limbs) ${ }^{36)}$. Sample items include "My job requires me to often bend or turn my wrist" and "My job requires me to keep my neck in a static position for a prolonged period of time." The items were measured on a 5-point scale, ranging from 1 (totally disagree) to 5 (totally agree). The average of all items was used in the analyses as an indicator of physical job demands.

Psychological and social job characteristics were measured with subscales of the Work Design Questionnaire (WDQ) ${ }^{37}$, each of which consisted of items that could be answered on a 5-point Likert scale ranging from 1 (totally disagree) to 5 (totally agree). Information processing was measured with 4 items, such as "My job requires me to monitor a great deal of information." Task complexity was also measured with four items; for example, "My job requires that I only do one task or activity at a time" (reverse coded). The task interdependence scale consisted of six items. A sample item is "The job requires me to accomplish my job before others complete their job." Decision latitude was measured with nine items; for example, "The job allows me to make my own decisions about how to schedule my work." Task variation was measured with five items, such as "The job involves doing a number of different things." The social support scale consisted of nine items; for example, "People I work with take a personal interest in me." Scores on the items were averaged per subscale as indicators of the job characteristics.

In order to measure short-term physical strain, surface EMG was used to measure muscular tension during execution of a low intensity computer task (typing text) in two muscle groups on the dominant arm (right or left), namely, the extensor digitorum and the trapezius transverses. Two disposable sticking electrodes $(\mathrm{Ag} / \mathrm{AgCl})$ were attached to the places associated with the muscle groups. The center of one of the electrodes was placed on the upper part of the trapezius transverses, and the other electrode was placed at about $4 / 5$ of the distance from the wrist to the elbow. While executing the computer task, the average EMG activity was computed for each muscle group over an interval of $10 \mathrm{~min}$. Before measuring the average EMG activity, the maximum EMG activity (EMGmax) was measured. For the trapezius transversus muscle, EMGmax was measured by shrugging the shoulders upwards as hard as possible, and for the extensor digitorum it was measured by making a tight fist. The ratio of average EMG to EMGmax is used as an indicator of short-term physical strain in the data analyses.

Subjective short-term psychological strain was measured with the average of a 7-item need for recovery scale ${ }^{38)}$. A sample item is "I find it difficult to relax at the end of a working day." The respondents were asked to rate their need for recovery on a 5-point scale, ranging from 1 (totally disagree) to 5 (totally agree).

\section{Statistical analysis}

Hypotheses were tested using hierarchical multiple regression analysis. Missing data were deleted listwise. Complete datasets were available for 105 respondents, which is more than the a-priori set minimum sample size of 100 respondents that is necessary for multiple regression analyses with ten predictors, estimated effect sizes of 0.20 and a statistical power level of 0.85 . Possible confounding variables were controlled for in the first step of the regression analyses. To investigate the mediating role of muscular tension and need for recovery, we followed steps as recommended by Baron and Kenny ${ }^{39)}$. In addition, we examined the strength of the indirect effect using a Sobel test ${ }^{40)}$.

\section{Results}

Table 1 presents the descriptive statistics. In line with our hypotheses, all job demands, except job complexity, had significant positive relationships with CANS and short-term strain, and decision latitude was significantly negatively related to physical demands, job complexity and to CANS. Both need for recovery and muscular tension were positively related to CANS.

\section{Hypotheses testing}

First, we tested whether physical, psychological and social job characteristics relate to CANS (see Table 2). As expected (Hypothesis 1b), high levels of psychological and social job demands (information processing and task interdependence) related positively to CANS. In contrast to our expectations (Hypothesis 1a), physical demands did not show a significant relationship with CANS over and above the effect of psychological job demands. Concerning job resources (Hypothesis 1c), only social support related significantly to less CANS.

To test the possible mediating effects of muscular tension (Hypothesis 2), we followed the steps of Baron and Kenny ${ }^{39)}$. That is, we first examined whether job demands were directly related to muscular tension. This was only the case for task interdependence $(\beta=0.40 ; p=0.00)$, but not for the other types of job demands. Next we found that muscular tension was directly related to CANS $(\beta=0.21 ; p=0.03)$. In the final step, we found that the effect of task interdependence on CANS remained significant after control- 


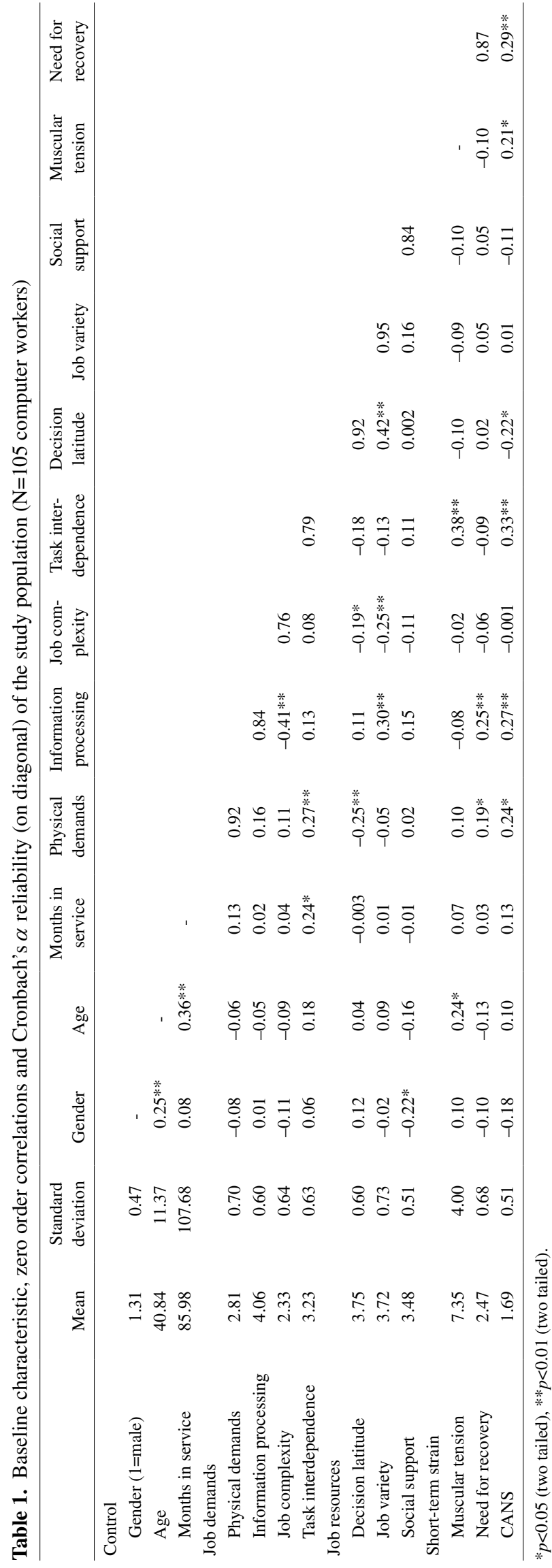

Table 2. CANS regressed on physical and psychosocial job characteristics $(\mathrm{N}=105$ computer workers)

\begin{tabular}{lcc}
\hline & Model 1 & Model 2 \\
\hline Predictors & $\beta$ & $\beta$ \\
Step 1 & & \\
$\quad$ Gender (1=male) & $-0.22^{*}$ & $-0.25^{* *}$ \\
$\quad$ Age & 0.11 & 0.08 \\
$\quad$ Months in service & 0.11 & 0.04 \\
Step 2 & & \\
$\quad$ Physical demands & & 0.06 \\
$\quad$ Information processing & & $0.28^{* *}$ \\
$\quad$ Job complexity & & 0.02 \\
$\quad$ Task interdependence & & $0.27^{*}$ \\
$\quad$ Decision latitude & & -0.19 \\
$\quad$ Social support & & $-0.24^{*}$ \\
$\quad$ Job variety & & 0.07 \\
$\mathrm{R}^{2}$ & & $0.30^{* * *}$ \\
$\mathrm{R}^{2}$ change & 0.07 & $0.24^{* * *}$ \\
\hline
\end{tabular}

$* p<0.05$ (two tailed), ${ }^{* *} p<0.01$ (two tailed), $* * * p<0.001$ (two tailed).

Table 3. CANS regressed on task interdependence and muscular tension ( $\mathrm{N}=105$ computer workers)

\begin{tabular}{lccc}
\hline Dependent variable: CANS & & & \\
\hline & Model 1 & Model 2 & Model 3 \\
\hline Predictors & $\beta$ & $\beta$ & $\beta$ \\
Step 1 & & & \\
$\quad$ Gender (1=male) & $-0.21^{*}$ & $-0.22^{*}$ & $-0.23^{*}$ \\
$\quad$ Age & 0.12 & 0.17 & 0.07 \\
$\quad$ Months in service & 0.13 & 0.13 & 0.07 \\
$\quad$ Step 2 & & & \\
$\quad$ Muscular tension & & $0.21^{*}$ & 0.12 \\
$\quad$ Step 3 & & \\
$\quad$ Task interdependence & & & $0.26^{*}$ \\
$\quad \mathrm{R}^{2}$ & 0.07 & $0.11^{*}$ & $0.16^{*}$ \\
$\mathrm{R}^{2}$ change & & $0.04 *$ & $0.06^{*}$ \\
\hline$* p<0.05$ (two tailed), $* * p<0.01$ (two tailed), $* * * p<0.001$ (two tailed).
\end{tabular}

ling for muscular tension (Table 3), meaning there is no evidence for a full mediation effect. However, a Sobel test ${ }^{40)}$ showed that the additional indirect effect of task interdependence on CANS through muscular tension was significant (Sobel=1.88; $p=0.03$ one tailed).

Finally, we tested Hypothesis 3, according to which need for recovery would mediate the relationship between job demands and CANS. First we found that information processing related to need for recovery $(\beta=0.25 ; p=0.04)$. In addition, need for recovery significantly predicted CANS $(\beta=0.29$; $p=0.002$ ). However, need for recovery did not fully mediate the relationship between information processing and CANS; this relationship remained significant after controlling for need for recovery (Table 4). A 
Table 4. CANS regressed on information processing and need for recovery ( $\mathrm{N}=105$ computer workers)

\begin{tabular}{lccc}
\hline Dependent variable: CANS & & & \\
\hline & Model 1 & Model 2 & Model 3 \\
\hline Predictors & $\beta$ & $\beta$ & $\beta$ \\
Step 1 & & & \\
$\quad$ Gender $(1=$ male) & $-0.22^{*}$ & $-0.20^{*}$ & $-0.21^{*}$ \\
$\quad$ Age & 0.11 & 0.15 & 0.16 \\
$\quad$ Months in service & 0.11 & 0.09 & 0.08 \\
Step 2 & & & \\
$\quad$ Need for recovery & & $0.29^{* *}$ & $0.24^{*}$ \\
Step 3 & & & \\
$\quad$ Information processing & & & $0.23^{*}$ \\
$\mathrm{R}^{2}$ & 0.07 & $0.15^{* *}$ & $0.10^{*}$ \\
$\mathrm{R}^{2}$ change & & $0.08^{* *}$ & $0.05^{*}$ \\
\hline
\end{tabular}

${ }^{*} p<0.05$ (two tailed), ${ }^{* *} p<0.01$ (two tailed), ${ }^{* * *} p<0.001$ (two tailed).

Sobel test, however, showed that the additional indirect effect through need for recovery was significant $(\text { Sobel }=1.76 ; p=0.04 \text {, one tailed })^{40)}$.

\section{Discussion}

Based on the Effort-Recovery model, this study among office workers investigated the role of physical, psychological and social job characteristics as predictors of CANS. We also examined the mediating role of short-term physical and psychological strain in this relationship.

In contrast to results of previous research findings ${ }^{6,7,12,13,15-19)}$ the results did not support the hypothesis that physical job demands would be associated with CANS over and above psychological and social job characteristics. Although we did find a significant first-order correlation between physical job demands and CANS, this relationship disappeared in multivariate analyses after entering psychological and social job characteristics, indicating that unfavorable psychological and social job characteristics are stronger CANS predictors for the office workers in our sample. A possible explanation for this discrepancy with other studies is that in the previous studies, physical risk factors were analyzed in isolation from psychological and social factors. So, part of the effect on CANS that was attributed to physical factors in these studies might actually have been due to psychological and/or social factors ${ }^{6,13,14)}$. Different results may also be attributable to different samples. In prior studies, psychological and social job characteristics were more important predictors for office and hospital workers, whereas physical predictors were more important predictors for manual workers ${ }^{27,31,33)}$.

Concerning psychological and social job demands, the extent to which office workers need to process information and task interdependence had strong relationships with CANS. No significant results were found for job complexity. Of the job resources under study, decision latitude, task variety and social support, only social support had a significant main effect. The results concur with other recent findings emphasizing that favorable psychological and social work conditions may prevent CANS ${ }^{18}$. It is well known that social support can reduce feelings of strain, thereby reducing the risk of developing stressrelated long-term health problems. In addition, social support may, for example, lower the threshold to seek professional help/treatment (colleagues give advice to seek professional help when early symptoms occur) and thus decrease the risk of CANS.

In line with the assumptions of previous stud$\operatorname{ies}^{24,26,27,30-35)}$ and of the ER model ${ }^{11)}$, our results further showed that muscular tension partially mediated the relationship between task interdependence and CANS and that need for recovery partially mediated the relationship between high information processing and CANS. This means that high job demands first result in a heightened muscular tension and tiredness in employees, which prolonged over time, could eventually result in long-term musculoskeletal disorders, such as CANS. This lines up with previous studies showing that general distress relates to increased muscular activity both during task execution and in rest $^{30)}$, and contrasts with results from Vasseljen and Westgaard $^{31)}$ that showed no relationship between psychological and social stressors and increased EMG activity in low-threshold motor units.

The findings of this study could guide future research as follows. First, the results on task interdependence, a job demand that was not studied before in previous research, indicate that it may be fruitful to explore the role of less commonly investigated psychological and social stressors in relation to CANS. Second, the findings concerning need for recovery indicate that future research should also examine which activities could facilitate recovery after work and thus reduce CANS.

This study has the limitations of a cross-sectional design and relying on subjective measures of job characteristics. A longitudinal design would be necessary to draw conclusions about causal pathways. As we only used subjective measures of physical demands, we do not know whether objective measures of the physical working environment might have been better predictors of CANS. Our results may also be job specific. This study investigated office workers. Although similar results have been found in other studies among office and hospital workers, the finding that psychological and social job characteristics are stronger predictors of CANS than physical characteristics might be different for other occupations, in particular blue collar workers. In our sample, the 
majority of office workers worked under similar physical conditions, which may be one of the reasons that the relatively small variation in these conditions did not really show relationships with CANS. Related to this, the working environment in which this study was performed was designed with attention to physical and ergonomic aspects, meaning that potential physical and ergonomic predictors of CANS may have been reduced to the extent that a floor effect of physical demands may have occurred.

Despite these limitations, our study has practical relevance. First, future interventions can be proactive by decreasing CANS risk through decreasing the amount of psychological job demands and increasing social job resources. We agree with Walker-Bone and Cooper $^{7)}$ and Lundberg et al. ${ }^{30)}$ that the effectiveness of neck schools or ergonomic improvements focusing on only physical aspects of the job will likely be disappointing for office workers. In addition, the partial intermediate effects of muscular tension and need for recovery that were found indicate that reactive interventions after assessing muscular tension or need for recovery of employees may be helpful as well. Workers may be identified who have an increased susceptibility and targeted for secondary preventive interventions to mitigate CANS in an early stage.

\section{Conclusion}

This study underscores that for office workers, psychological and social job characteristics are important predictors of long-term CANS that should not be neglected by occupational health professionals developing CANS prevention and mitigation programs. In addition, results of our study show that physical and psychological short-term strain, such as muscular tension and need for recovery, are both partial mediators in the relationship between job demands and CANS. This implies that, in addition to improving job design, assessment of muscular tension and need for recovery and reactive intervention could also reduce the occurrence of CANS.

\section{References}

1) Huisstede BM, Miedema HS, Verhagen AP, et al. Multidisciplinary consensus on the terminology of complaints of the arm, neck and/or shoulders. Occup Environ Med 2007; 64: 313-9.[PubMed] [CrossRef]

2) European Agency of Health and Work. OSH in figures: Work-related musculoskeletal disorders in the EU - Facts and figures. Luxembourg: Publications Office of the European Union. [Online]. 2010 [cited 2011 Jan 20]; Available from: URL: http://osha.europa.eu/en/publications/reports/ TERO09009ENC/view[PubMed] [CrossRef]
3) European Agency of Health and Work. Report Work-Related Neck and Upper Limb Musculoskeletal Disorders. Luxembourg: Office for Official Publications of the European Communities. [Online]. 1999 [cited 2011 Jan 20]; Available from: URL: http://osha. europa.eu/en/publications/reports/201/view [PubMed] [CrossRef]

4) Mullaly J, Grigg L. RSI: integrating the major theories. Aust J Psychol 1988; 40: 19-33. [PubMed] [CrossRef]

5) Hagberg M, Silverstein B, Wells R, et al. Workrelated musculoskeletal disorders (WMSDs): a reference book for prevention. London (UK): Taylor \& Francis; 1995: 201-40.[PubMed] [CrossRef]

6) Bongers PM, Winter CR, Kompier MA, et al. Psychosocial factors at work and musculoskeletal disease. Scand J Work Environ Health 1993; 19: 297-312.[PubMed] [CrossRef]

7) Walker-Bone K, Cooper C. Hard work never hurt anyone: or did it? A review of occupational associations with soft tissue musculoskeletal disorders of the neck an upper limb. Ann Rheum Dis 2005; 64: 1391-6.[PubMed] [CrossRef]

8) Bongers PM, Kremer AM, Ter Laak J. Are psychological factors, risk factors for symptoms and signs of the shoulder, elbow or hand/wrist? A review of the epidemiological literature. Am J Ind Med 2002; 41: 315-42.[PubMed] [CrossRef]

9) Ariëns GA,van Mechelen W, Bongers PM, et al. Psychosocial risk factors for neck pain: a systematic review. Am J Ind Med 2001a; 39: 180-94.[PubMed] [CrossRef]

10) Van Rijn RM, Huisstede BMA, Koes BW, Burdorf A. Associations between work-related factors and specific disorders of the shoulder - a systematic review of the literature. Scand J Work Environ Health 2010; 36: 189-201. [PubMed] [CrossRef]

11) Meijman TF, Mulder G. Psychological aspects of workload. In P.J.D. Drenth \& H. Thierry (Eds.), Handbook of work and organizational psychology: work psychology. Hove (UK): Psychology Press; 1998: 5-33.[PubMed] [CrossRef]

12) Andersen JH, Kaergaard A, Mikkelsen S, et al. Risk factors in the onset of neck/shoulder pain in a prospective study of workers in industrial and service companies. Occup Environ Med 2003; 60: 649-54.[PubMed] [CrossRef]

13) D'Errico, A, Caputo, P, Falcone, U, et al. Risk factors for upper extremity musculoskeletal symptoms among call center employees. J Occup Health 2010; 52: 115-24. [PubMed] [CrossRef]

14) Van der Windt AW, Thomas E, Pope DP, et al. Occupational risk factors for shoulder pain: a systematic review. Occup Environ Med 2000; 57: 433-42.[PubMed] [CrossRef]

15) Ariëns GA, Van Mechelen W, Bongers PM, et al. Physical risk factors for neck pain. Scand J Work Environ Health 2000; 26: 7-19.[PubMed] [CrossRef]

16) Cagnie B, Danneels L, Tiggelen $D$, et al. Individual and work related risk factors for neck pain among 
office workers: a cross-sectional study. Eur Spine J 2007; 16: 679-86.[PubMed] [CrossRef]

17) Green BN. A literature review of neck pain associated with computer use: public health implications. J Can Chiropr Assoc 2008; 52: 161-8.[PubMed] [CrossRef]

18) Ijmker S, Huysman MA, Blatter BM, et al. Should office workers spend fewer hours at their computer? A systematic review of the literature. Occup Environ Med 2007; 64: 211-22. [PubMed] [CrossRef]

19) Thomson JF, Mikkelsen S, Andersen, JH, et al. Risk factors for hand wrist disorders in repetitive work. Occup Environ Med 2007; 64: 527-33.[PubMed] [CrossRef]

20) National Research Council, Musculoskeletal Disorders and the Workplace: Low Back and Upper Extremities. Washington, DC: National Academy Press; 2001: 287-300.[PubMed] [CrossRef]

21) Janwantanakul P, Pensri P, Jiamjarasrangsi W, Sinsongsook T. Associations between prevalence of self-reported musculoskeletal symptoms of the spine and biopsychosocial factors among office workers. J Occup Health 2009; 51, 114-22. [PubMed] [CrossRef]

22) Carayon P, Smith M, Haims MC. Work organization, job stress, and work-related musculoskeletal disorders. Human Factors 1999; 41: 644-63. [PubMed] [CrossRef]

23) Feuerstein M, Shaw WS, Nicholas RA, et al. From confounders to suspected risk factors: psychosocial factors and work-related upper extremity disorders. J Electromyogr Kinesiol 2004; 14: 171-8.[PubMed] [CrossRef]

24) Van den Heuvel SG, Van der Beek AJ, Blatter BM, et al. Psychosocial work characteristics in relation to neck and upper limb symptoms. Pain 2005; 114: 47-53.[PubMed] [CrossRef]

25) Torp SM, Rijse T, Moen BE. The impact of psychosocial work factors on musculoskeletal pain: a prospective study. J Occup Environ Med 2001; 43: 120-6.[PubMed] [CrossRef]

26) Wahlström J, Hagberg $M$, Toomingas A, et al. Perceived muscular tension, job strain, physical exposure, and associations with neck pain among VDU users; a prospective cohort study. Occup Environ Med 2004; 61: 523-8.[PubMed] [CrossRef]

27) Wadman C, Kjellberg A. The role of affective stress response as a mediator for the effect of psychosocial risk factors on musculoskeletal complaints Part 2: hospital workers. Int J Ind Ergon 2007; 37: 395-403. [PubMed] [CrossRef]

28) Joling CI, Blatter BM, Ybema JF, et al. Can favorable psychosocial work conditions and high work dedication protect against the occurrence of workrelated musculoskeletal disorders? Scand J Work
Environ Health 2008; 34: 345-55.[PubMed] [CrossRef]

29) Leroyer AM, Edmé JL, Vaxevanoglou X, et al. Neck, shoulder, and hand and wrist pain among administrative employees: relation to work-time organization and psychosocial factors at work. J Occup Environ Med 2006; 48: 326-33.[PubMed] [CrossRef]

30) Lundberg U, Kadefors R, Melin B, et al. Psychophysiological stress and EMG activity of the trapezius muscle. Int $\mathbf{J}$ Behav Med 1994; 1: 354-70.[PubMed] [CrossRef]

31) Vasseljen O, Westgaard RH. A case-control study of trapezius muscle activity in office and manual workers with shoulder and neck pain and symptom-free controls. Pain 1995; 64: 221-30.[PubMed] [CrossRef]

32) Rietveld S, Beest I, Kamphuis JH. Stress-induced muscle effort as a cause of repetitive strain injury? Ergonomics 2007; 50: 2049-58.[PubMed] [CrossRef]

33) Kjellberg A, Wadman C. The role of the affective stress response as a mediator of the effect psychosocial risk factors on musculoskeletal complaints part 1: assembly workers. Int J Ind Ergon 2007; 37: 367-74. [PubMed] [CrossRef]

34) Hoogendoorn WE, Bongers PM, De Vet HC, et al. Psychosocial work characteristics and psychological strain in relation to low-back pain. Scand J Work Environ Health 2001; 27: 258-67.[PubMed] [CrossRef]

35) Byström P, Johansson HJ, Kjellberg A. Appraised psychological workload, musculoskeletal symptoms, and the mediating effect of fatigue: a structural equation modeling approach. Scand J Psy 2004; 45: 331-41.[PubMed] [CrossRef]

36) Hildebrandt VH, Bongers PM, van Dijk FJ, et al. Dutch Musculoskeletal Questionnaire: description and basic qualities. Ergonomics 2001; 44: 1038-55.[PubMed] [CrossRef]

37) Morgeson FP, Humphrey SE. The Work Design Questionnaire (WDQ): developing and validating a comprehensive measure for assessing job design and the nature of work. J Appl Psychol 2006; 91: 1321-39.[PubMed] [CrossRef]

38) Van Veldhoven M, Broersen S. Measurement quality and validity of the need for recovery scale. Occup Environ Med 2003; 60: i3-i9.[PubMed] [CrossRef]

39) Baron RM, Kenny DA. The moderator-mediator variable distinction in social research: conceptual, strategic and statistical considerations. J Pers Soc Psychol 1986; 51: 1173-82.[PubMed] [CrossRef]

40) Sobel ME. Asymptotic intervals for indirect effects in structural equation models. In: S. Leinhart (Ed.), Sociological methodology. San Francisco (CA): Jossey-Bass; 1982: 290-312.[PubMed] [CrossRef] 